City University of New York (CUNY)

CUNY Academic Works

\title{
Immunohistochemical Localization of Prolactin Receptor (PRLR) to Hodgkin's and Reed-Sternberg Cells of Hodgkin's lymphoma
}

\author{
Rajendra Gharbaran \\ CUNY Bronx Community College \\ Onyekwere Onwumere \\ CUNY Lehman College \\ Naomi Codrington \\ CUNY Lehman College \\ Latchman Somenarian \\ CUNY Bronx Community College \\ Stephen Redenti \\ CUNY Lehman College
}

\section{How does access to this work benefit you? Let us know!}

More information about this work at: https://academicworks.cuny.edu/bx_pubs/88

Discover additional works at: https://academicworks.cuny.edu

This work is made publicly available by the City University of New York (CUNY).

Contact: AcademicWorks@cuny.edu 
Short communication

\title{
Immunohistochemical localization of prolactin receptor (PRLR) to Hodgkin's and Reed-Sternberg cells of Hodgkin's lymphoma
}

\author{
Rajendra Gharbaran $^{\mathrm{a}, *}$, Onyekwere Onwumere ${ }^{\mathrm{b}, \mathrm{c}}$, Naomi Codrington ${ }^{\mathrm{b}}$, \\ Latchman Somenarain $^{\text {a }}$, Stephen Redenti ${ }^{\text {b,c }}$ \\ ${ }^{a}$ Department of Biological Sciences, Bronx Community College/City University of New York, Bronx, NY, USA \\ ${ }^{\mathrm{b}}$ Department of Biological Sciences, Lehman College/City University of New York, Bronx, NY, USA \\ ${ }^{\mathrm{c}}$ Biology Doctoral Program, The Graduate School and University Center, City University of New York, 365 5th Avenue, New York, NY 10016, USA
}

\section{A R T I C L E I N F O}

\section{Keywords:}

Hodgkin's lymphoma

Reed-Sternberg

Prolactin receptor

Cancer

Immunohistochemistry

\begin{abstract}
A B S T R A C T
Prolactin receptor (PRLR), a type-1 cytokine receptor, is overexpressed in a number of cancer types. It has attracted much attention for putative pro-oncogenic roles, which however, remains controversial in some malignancies. In this study, we reported the localization of PRLR to the Hodgkin's and Reed-Sternberg (HRS) cells of Hodgkin's lymphoma (HL), a neoplasm of predominantly B cell origin. Immunohistochemistry performed on 5$\mu \mathrm{m}$ thick FFPE sections revealed expression of PRLR in HRS cells. Cellular immunofluorescence experiments showed that the HL-derived cell lines, Hs445, KMH2 and L428 overexpressed PRLR. The PRLR immunofluorescent signal was depleted after treating the cell lines with $10 \mu \mathrm{M}$ of siRNA for $48 \mathrm{~h}$. We also tested whether PRLR is involved in the growth of HL, in vitro. One-way analysis of variance (ANOVA) on cell growth data obtain from WST-1 cell proliferation assay and trypan blue exclusion assay and hemocytometry showed that siRNAdepletion of PRLR expression resulted in decreased growth in all three cell lines. These results offered only a short insight into the involvement of PRLR in HL. As a result, further investigation is required to decipher the precise role(s) of PRLR in the pathogenesis of HL.
\end{abstract}

\section{Introduction}

Overexpression of hormone receptors have been reported for a number of cancer types, a phenotype that is suspected disease in development and progression. One such receptor is the prolactin receptor (PRLR), a type-1 cytokine receptor, although its putative prooncogenic roles remain controversial in some malignancies. Overexpression of PRLR has been reported for a growing list of cancer types including cancers of the ovaries (Sundaram et al., 2017), cervix (Lopez-Pulido et al., 2013), breasts (Hachim et al., 2016) prostate (Sackmann-Sala et al., 2014), colon and rectum (Harbaum et al., 2010). In some cancers PRLR overexpression is associated with an adverse prognosis (Shemanko, 2016; Taylor et al., 2010). Among lymphomas, there is only a paucity of information of PRLR expression. PRLR expression has been reported for rat Nb2 T lymphoma cells (Shiu et al., 1983) and a limited number of human non-Hodgkin's lymphoma (NHL) cell lines, including Daudi cells (Matera et al., 2000). PRL, one of the cognate ligands for PRLR, appears to be non-mitogenic to PRLR-positive
NHL cell lines (Matera et al., 2000).

Hodgkin's lymphoma (HL) is a unique B-cell neoplasm characterized by giant mononuclear Hodgkin's and multi-nuclear Reed-Sternberg (HRS) cells, which make up less than $1 \%$ of the tumor. Previous studies showed activated signal transducer and activator transcription 5 (STAT5) in HRS cells of a subsets of HL patients (Martini et al., 2008) and in vitro experiments showed that activation of STAT5 resulted from IL-21 interaction with IL-21 R (Scheeren et al., 2008). PRLR activities are mediated via JAK2/STAT5 signaling. However, the current status of PRLR in HL is largely unknown. Thus, this report gives a brief insight into involvement of PRLR in HL. Immunohistochemistry (IHC) analyses using two different primary antibodies (an anti-mouse PRLr-ECD- mAb 1A2B1 and and anti-rabbit PRLR- pAb H-300) showed strong PRLR staining in the HRS cells in clinical specimen examined. PRLR immunofluorescent signal detected in cell lines stained with mAb 1A2B1 antibody, was depleted after treatment with $10 \mathrm{u} \mathrm{M}$ of siRNA for $48 \mathrm{~h}$. We also tested whether PRLR is involved in the growth of HL, in vitro. WST-1 cell proliferation assay and trypan blue exclusion assay and

\footnotetext{
* Corresponding author at: Biological Sciences Department, Bronx Community College/The City University of New York, 2155 University Ave, Bronx, NY 10453, USA.

E-mail address: rajendra.gharbaran@bcc.cuny.edu (R. Gharbaran).
} 
hemocytometry showed that siRNA-knockdown of PRLR expression resulted in decreased growth in all lines. To the best of our knowledge, this is the first report of PRLR expression in HL. Given reports of pro-oncogenic roles of PRLR, further research is warranted to gain insights into the role of PRLR in pathogenesis of HL.

\section{Methods and materials}

\subsection{Cell lines and cell cultures}

The human HRS-derived cell lines KMH2 and L428 were obtained from the German Collection of Microorganisms and Cell Cultures (DSMZ), Department of Human and Animal Cell Cultures, Braunschweig, Germany in April 2017. Hs445 was obtained from the American Tissue and Cell Collection -ATCC- (Manassas; VA, USA) in March 2017. L428 and KMH2 were cultured in RPMI 1640 medium supplemented with $10 \%$ heat-inactivated fetal bovine serum (FBS) [Gibco, Gaithersburg; MD, USA cat. \#: 10437028, lot \#: 1623737], 1\% Lglutamine (Thermo Fisher Scientific, Waltham; MA, USA, cat\#: 25030081) and penicillin/streptomycin (Thermo Fisher Scientific, cat \#: 15140148). Culture media Hs 445 were similar but contained $20 \%$ heatinactivated FBS. Cells used in these experiments were from early passage (L428 and KMH2 passage 3, and Hs445, passage 4) and they were treated for mycoplasma and subsequently tested negative as described by Uphoff et al. (1992, 2002). All cells were maintained in a humid environment of $5 \% \mathrm{CO}_{2}$ at $37^{\circ} \mathrm{C}$.

\subsection{Immunohistochemistry}

Tissue sections used in this study were purchased from OriGene Technologies (Rockville; MD, USA) and from US BioMax (Derwood; MD, USA). These companies provided documentation regarding approval of tissue for clinical observation. Also, our institution does not require IRB approval for studies on tissues procured from commercial sources. IHC was carried out on xylene-dewaxed, degraded alcohol (100, 80, 70, 50 $\%)$, PBS (Thermo Fisher Scientific, MA, USA, cat. \#: 10010023)-rehydrated, 5- $\mu \mathrm{m}$ FFPE tissue sections, as described by Gharbaran et al. (2019) with minor modifications. Endogenous peroxidases were quenched by incubating the sections in $3 \% \mathrm{H}_{2} \mathrm{O}_{2}$ solution in PBS for 10 min followed by rapid washes in PBS at room temperature. Section were blocked at room temperature for $2 \mathrm{~h}$ with $1 \%$ BSA containing $5 \%$ normal goat serum (Sigma-Aldrich, Saint Luis; MO, USA, cat. \#: G9023) in PBS, followed by overnight incubation at $4{ }^{\circ} \mathrm{C}$, in either a mouse monoclonal anti-PRLr-ECD antibody (mAb clone 1A2B1) [Invitrogen, Carlsbad; CA, USA—cat. \#: 359200, lot \#: 1529262A], diluted 1:100 or a rabbit polyclonal anti-PRLR antibody (pAb H-300) [Santa Cruz Biotechnology, Dallas; TX, USA—cat. \#: sc-20922, lot \#: J1910, clone $\mathrm{H}-300$ ] diluted at 1:200. Signal detection was carried out using an LSAB kit according to the manufacturer's instructions (Agilent DAKO, Santa Clara; CA, USA, cat. \#: K0672). The sections were counterstained with Gill's hematoxylin (Vector Labs, Burlington; ON, Canada, cat. \#: $\mathrm{H}-3401$ ) for $22 \mathrm{~s}$ and immediately washed in tap water before mounting with VectaMount aqueous mounting media (Vector Labs, cat. \#: H-5501). Photomicrographs of stained tissues were generated with a Leica MC190 HD Camera coupled to a Leica DM2500 microscope (Leica Microsystems, Richmond Hill; ON, Canada). Preparation of negative controls follows all steps except without incubation in primary antibody.

\subsection{Cellular immunofluorescence}

Cellular immunofluorescence steps were similar to those for IHC with some modifications. Cells were adhered to poly-D lysine (SigmaAldrich, MO, USA cat. \#: 27964-99-4) coated number 1 coverslips for $30 \mathrm{~min}$ in a humid chamber at $37^{\circ} \mathrm{C}$ in $5 \% \mathrm{CO}_{2}$, rinsed $1 \times$ with PBS then fixed for 20 min with $3.7 \%$ paraformaldehyde (Electron Microscopy Sciences 15710, Hatfield; PA, USA). Fixed cells were permeabilized with $0.1 \%$ PBS-TX100 (Triton X-100 purchased from Sigma-Aldrich, MO, US, cat. \#: T9284) for $30 \mathrm{~min}$ then blocked for $30 \mathrm{~min}$ in $1 \%$ normal goat serum followed by incubation in primary antibody (mAb 1A2B1) diluted 1:400 in blocking buffer for $1 \mathrm{~h}$. Stained cells were mounted in ProLong Gold anti-fade reagent containing DAPI (Life Technologies, Carlsbad; CA, USA, cat. \#: P36931) and images were captured with a CoolSNAP HQ2 CCD camera (Cool SNAP EZ, Photometrics, Tucson; AZ, USA) coupled to a Nikon Ti Eclipse inverted microscope (Melville, NY, USA).

\subsection{RNA isolation, $c D N A$, and $q P C R$}

Total RNA was isolated by Trizol (Life Technologies, Carlsbad; CA, USA, cat. \# 155960218) according manufacture instructions. cDNA was prepared by ProtoScript ${ }^{\circledR}$ II First Strand cDNA Synthesis Kit (New England BioLabs, Rowley; MA, USA, cat. \#: E6300S) according manufacturer's instructions, from $50 \mathrm{ng}$ of RNA per reaction. For qPCR, each reaction consisted of $10 \mathrm{ng}$ cDNA, $10 \mathrm{mM}$ primers and $10 \mu \mathrm{l}$ 2X SYBR GreenER $^{\mathrm{TM}}$ qPCR SuperMix (Life Technologies, cat. \#: 11761-100). Reactions were carried out in a MicroAmp Fast Optical 96-Well Reaction Plate on a BioRad Icycler Thermal Cycler. The reaction was performed using the standard mode (initial denaturation at $95^{\circ} \mathrm{C}$ for $10 \mathrm{~min}$ followed by 40 cycles of $95^{\circ} \mathrm{C}$ for $15 \mathrm{~s}$ and $60^{\circ} \mathrm{C}$ for $1 \mathrm{~min}$ ). Each qPCR reaction was done in triplicate. The amount of target mRNA was normalized to the expression levels of the housekeeping gene GAPDH. GAPDH primer pair were $5^{\prime}$-cat ggc ctc caa gga gta ag-3' and $5^{\prime}$-agg ggt ctac atg gca act $\mathrm{g}-3^{\prime}$ for forward and reverse sequences, respectively, and those for PRLR were $5^{\prime}$-tggtctgaaggggtcaatc- $3^{\prime}$ and $5^{\prime}$-ccccagagctaaactgcaac- $3^{\prime}$ for forward and reverse sequences, respectively. The $\Delta \Delta \mathrm{Ct}$ method was used to calculate the fold-change relative to controls.

For detection of PRL in parental cell lines by qPCR, the primer forward and reverse sequences were $5^{\prime}$ - cat cat cag ctg cca cac $-3^{\prime}$ and $5^{\prime}$ - cca cgt act tcg gtg gac cag $-3^{\prime}$, respectively.

\section{5. siRNA knockdown of PRLR expression}

$1 \times 10^{5}$ cells $/ \mathrm{mL}$ cultured in 24-well plates overnight were treated with $10 \mu \mathrm{M}$ of siRNA to PRLR (Dharmacon, CO, USA, cat \#: L-00630400-0005-ON-TARGETplus SMARTpool) for $48 \mathrm{~h}$. In brief, siRNA was complexed with Lipofectamine RNAiMax (Invitrogen, cat. \#: 13778075; lot \#: 2018673) in Opti-MEM reduced serum media (Gibco, cat. \#: 31985070; lot \#: 2003883) in 1 x siRNA buffer (Dharmacon, cat \#: B002000-UB-100), before applying to cultured cells. The sequence of siRNAs included in the ON-TARGETplus SMARTpool from Dharmacon, consists of the following sequences: CCGCUAAACCCUUGGAUUA (siRNA J-006304-07), UCAGAUACCUAGUGACUUC (siRNA J-00630408), CACCAUCACUUGAACAGAA (siRNA J-006304-09), and GCAUGAAUGUCCAGACUAC (siRNA J-006304-10). In these experiments, control cells were treated with scrambled, non-targeted siRNA (NT_siRNA) (OriGene Technologies, cat \#: SR30004).

\subsection{WST-1 cell proliferation assay}

$1 \times 10^{5}$ cells $/ \mathrm{mL}$ plated in 96-well plates overnight and treated with $10 \mu \mathrm{M}$ each of PRLR siRNA for $48 \mathrm{~h}$ were incubated in indicated culture conditions. Cell growth was assessed with WST-1 cell proliferation assay (Roche, Branchburg; NJ, USA, cat \#: 11644807001, lot \#: 14310400), according to manufacturer's instructions and as described by Gharbaran et al. (2019). Absorbance was read at $450 \mathrm{~nm}$ on a Synergy H1 Hybrid microplate reader (BioTek Instruments, Winooski; VT, USA). Cell growth (in percentages, \%) was computed as a ratio of either the absorbance (A450) of PRLR_siRNA or NT_siRNA-treated and absorbance $(\mathrm{A} 450 \mathrm{~nm})$ of untreated control (A450 nm). 


\subsection{Trypan Blue exclusion assay and automated hemocytometry}

Trypan blue exclusion assay was carried out using EVE Automated Cell Counter (NanoEntek, Guro-gu; Seoul, South Korea) according to manufacturer's instructions. In brief, $10 \mu \mathrm{l}$ of cell suspension was mixed with $10 \mu \mathrm{l} 0.4 \%$ trypan blue then loaded into counting chamber.

\subsection{Mapping of siRNA to putative PRLR isoforms}

We used a bioinformatics approach to the association of each siRNA with specific PRLR isoforms. To do this, we BLAST each of the manufacturer's-derived siRNA sequence against publicly available human nucleotide sequences. The list of output for each siRNA was manually searched using the "Command $+F$ " search function on an Apple Macbook Air (Early 2014), using search terms related to PRLR isoforms: transcript variant, delta S1, truncated, intermediate isoform, short isoforms, etc.

\subsection{Statistical analyses}

Data analyses were performed using SAS 9.1.3 (SAS Institute Inc., Cary; NC, USA) and StatView 5 (SAS Institute Inc.). Absorbance data

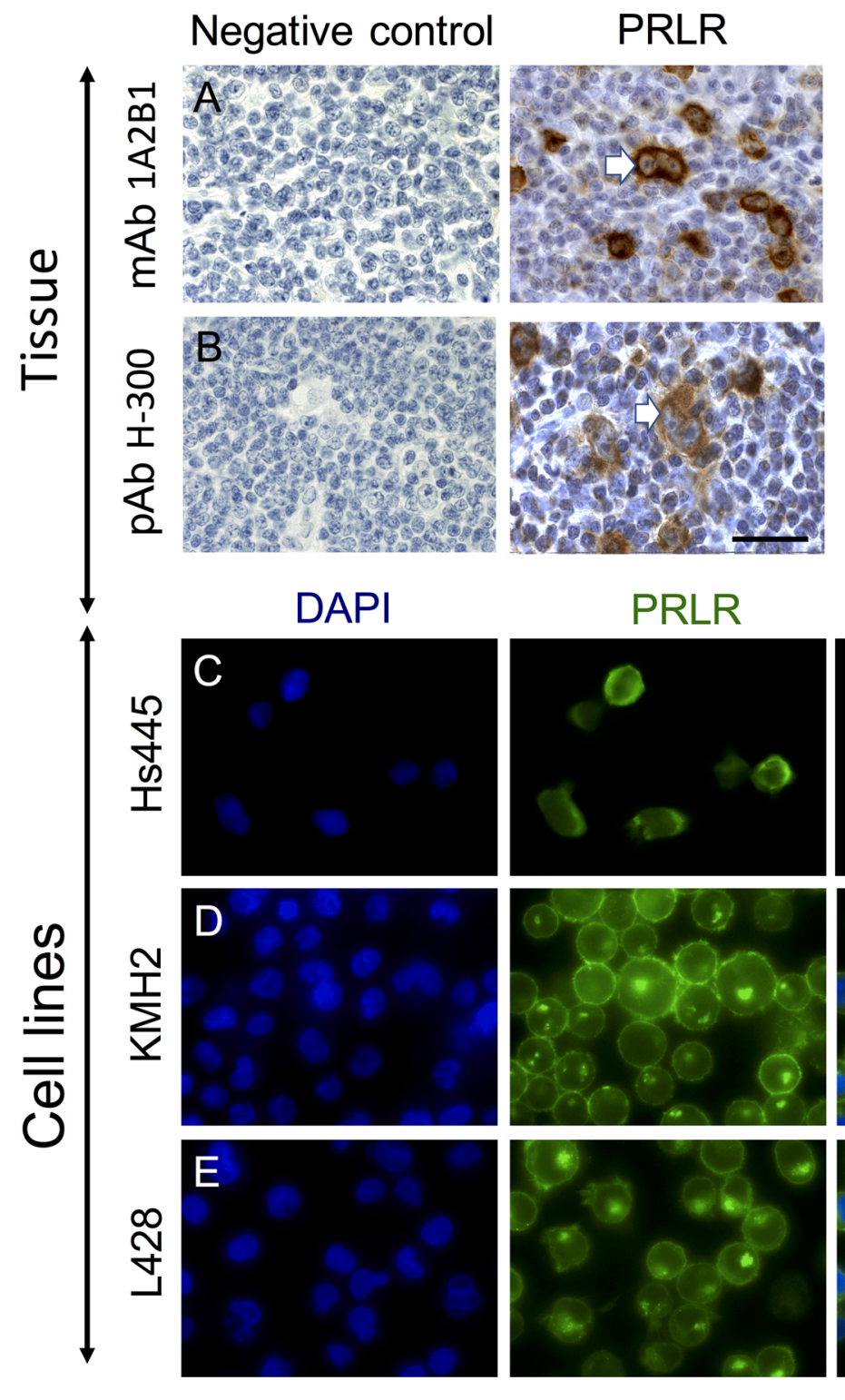

reflecting cell growth were presented as standard error of the mean (SEM) derived from triplicates. Analysis of variance (ANOVA) and F statistics were used to determine differences between the means as defined by $\mathrm{p}<0.05$. Each experiment was repeated at least three times.

\section{Results}

\subsection{Antibodies}

The antibodies used in our study, mAb 1A2B1 and pAb H-300, were among six commercial antibodies evaluated for specificity to human PRLR expression in breast cancer (Galsgaard et al., 2009). Although both $\mathrm{mAb} 1 \mathrm{~A} 2 \mathrm{~B} 1$ and $\mathrm{pAb} \mathrm{H}-300$ produced better IHC staining than the other antibodies tested, the authors determined that 1A2B1 was more useful for IHC applications. Such evaluation is critical for accuracy in clinical diagnosis. The mAb 1A2B1 antibody recognize the ectodomain portion of the PRLR protein and pAb H-300 antibody was generated against an epitope corresponding to amino acids 323-622 mapping at the C-terminus of the human PRLR, as per manufacturer's information and Galsgaard et al. (Galsgaard et al., 2009).

Because there is little or no information about the evaluation of these antibodies in lymphoma, we had to determine the optimal dilution of
Fig. 1. Tissue and cell line expression of PRLR. A-B. IHC detection of PRLR in HRS cells using $\mathrm{mAb} 1 \mathrm{~A} 2 \mathrm{~B} 1$ and $\mathrm{pAb} \mathrm{H}-300$, respectively. C-E. Immunofluorescence detection of PRLR expression using mAb 1A2B1, in HL-derived cell lines Hs445, KMH2 and L428, respectively. In $\mathrm{A}$ and $\mathrm{B}$, negative controls are presented in left panels and arrows in right panels point to representative classic HRS cells. Scale bar $=100 \mu \mathrm{m}$.
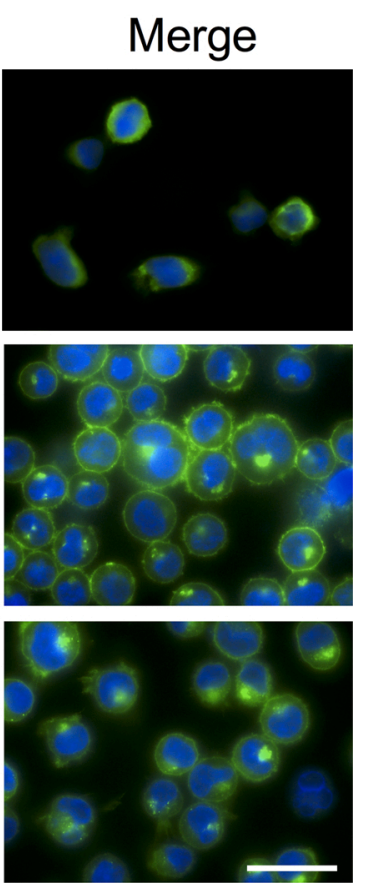
each for IHC and ICC. The optimal dilution of antibodies used for either IHC or ICC were determined via serial dilution. From this titration process, we determined that mAb 1A2B1 works optimally at 1:400 and 1:100 dilution for ICC and IHC respectively. Similar analyses resulted in application of pAb H-300 at 1:200 dilution for IHC.

\subsection{Expression of PRLR in primary Hodgkin's and Reed-Sternberg cells and $H L$ cell lines}

We used the mAb 1A2B1 and pAb H-300 antibodies to study the expression of PRLR on histological sections of HL. PRLR positivity was seen in all clinical specimen $(n=6$ for each of mAb 1A2B1 and pAb H300). The HRS cells were among the cells that overexpressed PRLR (Fig. 1a-b). These cells showed similar levels of expression of PRLR across clinical specimen for the respective antibody used. However, the staining with mAb 1A2B1 appeared stronger. PRLR staining in HRS cells appeared to be localized to the cytoplasm and the cell membrane.

Immunofluorescent staining using the mAb 1A2B1 showed expression of PRLR in all three HL-derived cell lines (Hs445, KMH2, L428) studied (Fig. 1c-e). This antibody detected cell membrane and cytoplasmic PRLR expression in Hs445, but predominantly cell membrane PRLR signal for KMH2 and L428 cells. A subset of these latter cells also displayed subcellular punta, the origins of which remain unclear in these cells in this study. However, although the puncta are relatively large, other studies showed PRLR can undergo internalization, appearing as bright punctate spots in confocal microscopy images (Genty et al., 1994; Perrot-Applanat et al., 1997). Every cell within each viewing field observed for each cell line appeared to express PRLR. Like the primary HRS cells, cell membrane expression of PRLR appeared robust among cell lines.

\subsection{Nature of siRNAs and putative PRLR isoforms in $H L$}

Studies in breast and prostate cancers revealed that there are multiple putative isoforms of the human PRLR gene (Abramicheva and Smirnova, 2019; Griffith et al., 2016; Shemanko, 2016), presumably a consequence of alternative splicing and in some instances a result of mutations. As a consequence, we conducted a search to determine the putative predicted isoforms or transcript variants associated with PRLR siRNA used in this study. siRNA J-006304-07 (sequence: CCGCUAAACCCUUGGAUUA) was mapped to transcript variants transcript variant $1,6, \mathrm{X} 1, \mathrm{X} 2, \mathrm{X} 3, \mathrm{X} 4, \mathrm{X} 5, \mathrm{X} 6$, delta S1 precursor. siRNA J-006304-08 sequence UCAGAUACCUAGUGACUUC was associated with transcript variant transcript variant $1,2,3,4,5,6,7, \mathrm{X} 1, \mathrm{X} 2, \mathrm{X} 3$, $\mathrm{X} 4$, X5, X6, delta S1 precursor, delta 4-SF 1B, intermediate isoform, short isoforms $1 \mathrm{a}, 1 \mathrm{~b}, 1 \mathrm{c}$. The predicted transcript variants for siRNA J-006304-09 (sequence: CACCAUCACUUGAACAGAA) include transcript variant 1, 2, 6, X1, X1, X2, X3, X4, X5, X6, delta S1 precursor, intermediate isoform. And siRNA J-006304-10 sequence GCAUGAAUGUCCAGACUAC appears to target transcript variant 1, 2, 3, 4, 5, 7, X1, $\mathrm{X} 2, \mathrm{X} 3, \mathrm{X} 4, \mathrm{X} 5, \mathrm{X} 6$, delta $\mathrm{S} 1$ precursor, delta 4-SF1b truncated, delta-4-delta 4/11 truncated, intermediate isoform, and short isoforms $1 \mathrm{a}, 1 \mathrm{~b}, 1 \mathrm{c}$. Intriguingly, although the siRNAs showed $100 \%$ similarity with the PRLR variants, transcript variant 5 reported for siRNA J-006304-08 showed only $73 \%$ similarity. This data suggest that each siRNA used in the PRLR knockdown experiments may target multiple isoforms.

\section{4. siRNA knockdown of PRLR reduced cell growth}

PRLR overexpression has been implicated in growth and survival of cancer cells. Therefore, we studied whether PRLR expression influences growth of HL, in vitro. Cells treated with $10 \mu \mathrm{M}$ of siRNA to PRLR for $48 \mathrm{~h}$ showed loss of immunofluorescent signal and decreased levels of PRLR transcripts compared to untreated or NT_siRNA controls (Hs445, $\mathrm{p}<0.05 ; \mathrm{KMH} 2, \mathrm{p}<0.05 ; \mathrm{L} 428, \mathrm{p}<0.007)$, indicating decreased expression of the protein (Fig. 2a-c). In these experiments, the $\mathrm{Ct}$ values for PRLR in parental Hs445 were 24.19, 24.97, 23.81, for KMH2 these values were 25.18, 23.97, 24.91, and for L428, 24.58, 24.69, 24.91. These values were comparable to those generated from cells treated with NT_siRNA and from cells treated with lipofectamine reagent alone.

One-way ANOVA on WST-1 cell proliferation data showed statistically significant difference in mean cell growth between NT_siRNA and PRPL_siRNA treatment for each cell line of Hs445 ( $<0.02), \mathrm{KMH} 2$ $(\mathrm{p}<0.001)$ and L428 $(\mathrm{p}<0.001)$ [Fig. 2d]. Similar results were also observed for trypan blue exclusion assay and hemocytometry: Hs445 $(\mathrm{p}<0.008)$ KMH2 $(\mathrm{p}<0.005)$ and L428 $(\mathrm{p}<0.002)$ [Fig. 2e]. These results indicated that PRLR may be involved in growth of HL.

\subsection{Expression of PRL by $H L$ cell lines}

Although PRL has been shown to be non-mitogenic to lymphoma cells (Matera et al., 2000) PRLR_siRNA-induced decreased growth of HL cell lines suggest a putative PRLR-dependent growth mechanism. As PRL contained in FBS does not significantly activate human PRLR (Utama et al., 2009) we studied HL cell lines for PRL expression using qPCR to gain insight into a putative PRL-PRLR axis autocrine growth mechanism. The average $\mathrm{Ct}$ value for each cell line was 26.82 , 28.58, and 24.79 for Hs445, KMH2, and L428, respectively. Future studies are needed to determine whether PRL is important for growth of HL cells via PRLR activation.

\section{Discussion}

The overexpression of hormone receptors has been reported for a growing number of cancer types. Such receptors include those for growth hormone, estrogens, androgens, and prolactin. Here, we offer brief insights into the involvement of PRLR in HL. The IHC analyses showed that PRLR is overexpressed by primary HRS cells, using two different antibodies.

We also showed that PRLR is expressed by HL-derived cell lines Hs445, KMH2, and L428, using immunofluorescent staining. As with the primary HRS cells, robust cell membrane expression of PRLR was detected in the cell lines and the expression pattern appeared in almost $100 \%$ of the cells in the microscopic viewing fields of all three cell lines. Cell line expression of PRLR was depleted with siRNA treatment, which also reduced cell growth. In addition, qPCR showed varying levels cell line expression of PRL, one of the cognate ligands of PRLR, indicating a putative autocrine mechanism of cell growth, which warrants further research.

Although not shown in our data, PRLR signaling occurs predominantly via the JAK2/STAT5 signaling pathway. Therefore, PRLR may be one of several JAK2-STAT5 dependent receptors aberrantly active in HL (Martini et al., 2008; Scheeren et al., 2008). Activated JAK2/STAT5 mediates the action of a multiple cytokines contributing to increased cytokine release, inflammation and pathogenesis, in HL. For example, interleukin-21 (IL-21) which is highly expressed by HRS cells, activates STAT5 in HL lymphomagenesis (Scheeren et al., 2008) and mediates the recruitment of regulatory $\mathrm{T}$ cells (Treg) via STAT3 activation (Lamprecht et al., 2008). Treg infiltration in the HL tumor microenvironment may be used to predict outcome (Alvaro et al., 2005). Other putative PRLR-dependent signaling cascades include those related to cell proliferation (e.g. RAS/RAF/MAPK) (Das and Vonderhaar, 1996), anti-apoptosis (Ramirez de Arellano et al., 2015) and cell motility (e.g. P13-K) (Maus et al., 1999). Although these signaling cascades are also deregulated in HL (Aravinth et al., 2019; Wallentine et al., 2007), further studies will be needed to determine if their activities are in part, PRLR-dependent in this B cell malignancy.

\section{Funding}

Support for this project was provided in part by a PSC-CUNY Award, 

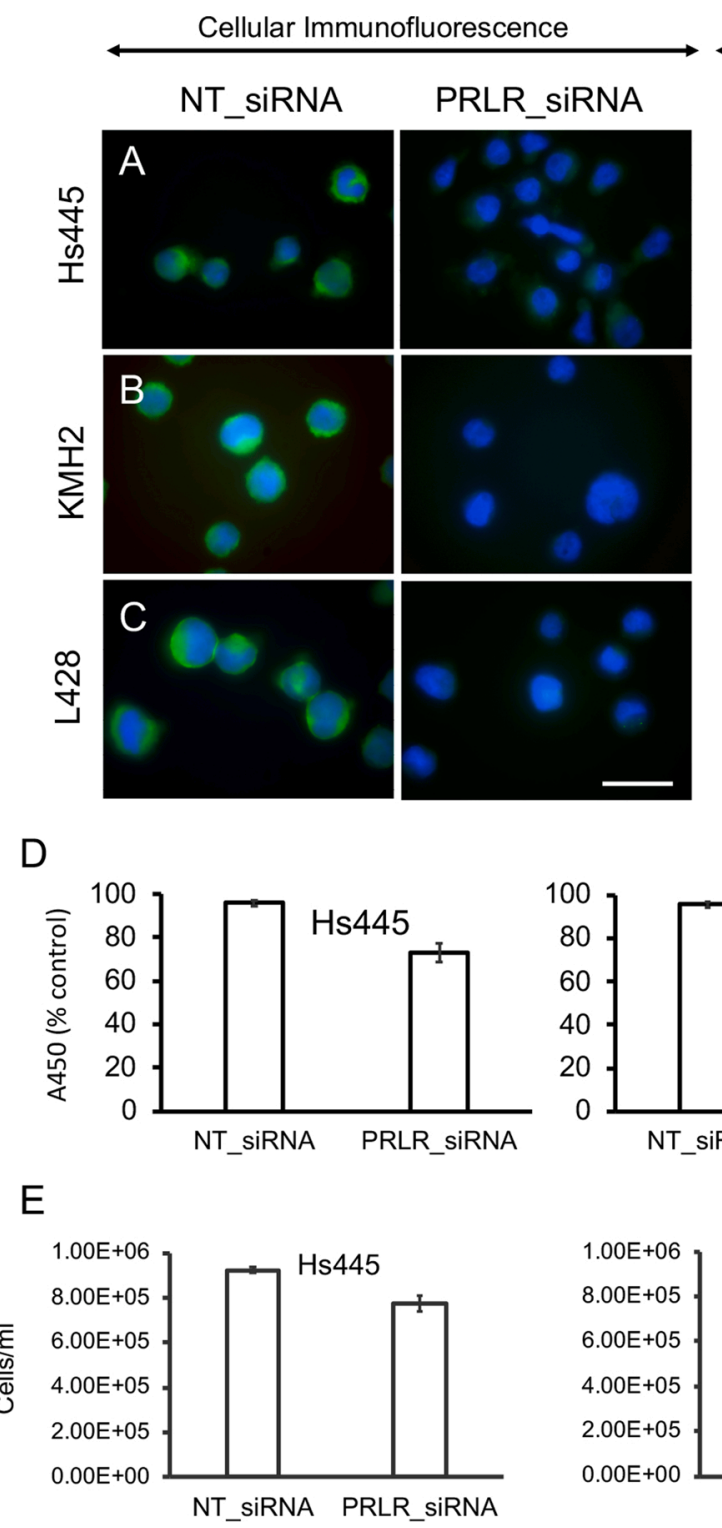
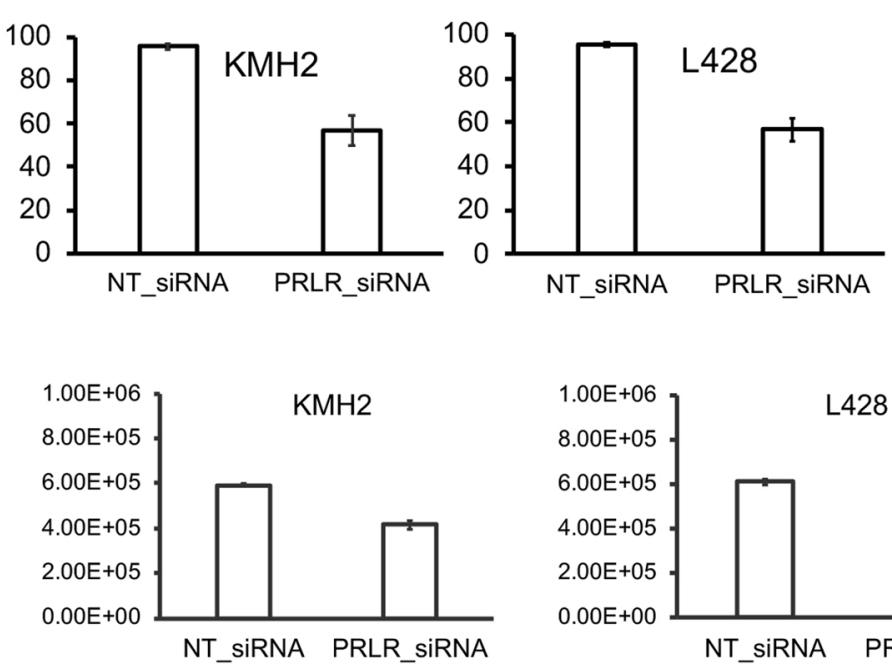

qPCR
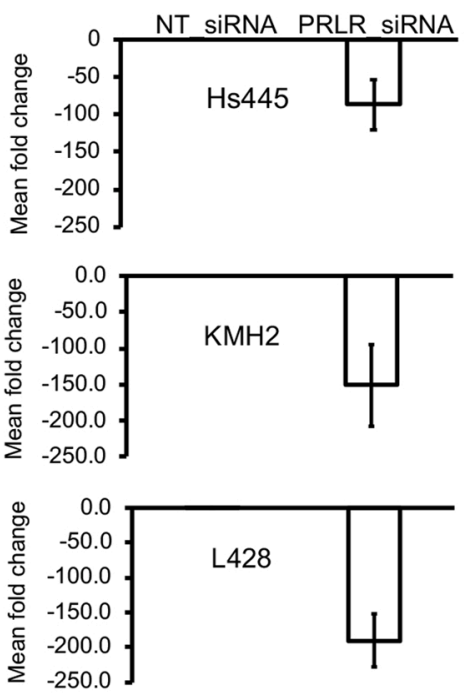

Fig. 2. siRNA knockdown of PRLR and reduced cell growth.

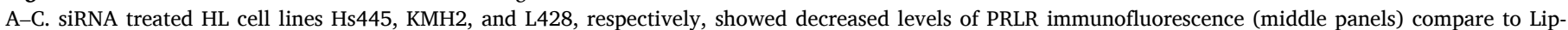
ofectamine (LipoFec) controls (right panels). siRNA-induced decrease in PRLR expression is supported by qPCR data (right panels) for each cell line. D-E. Cell growth curves of WST-1 and hemoctometry data, respectively. siRNA to PRLR resulted in decreased growth of all three cell lines.

Data for each experiment was obtain from triplicates. Each experiment was repeated at least three times. Error bars in graphs represent standard error.

jointly funded by The Professional Staff Congress and The City University of New York (Award \#: TRADB-48-360), and The City University of New York Community College Research Grant (Award \#: 80212-03-17).

\section{Informed consent}

Not Applicable

\section{Ethical approval}

This article does not contain any studies with human participants or animals performed by any of the authors.

\section{CRediT authorship contribution statement}

Rajendra Gharbaran: Conceptualization, Investigation, Methodology, Data curation, Writing - original draft, Writing - review \& editing,
Supervision. Onyekwere Onwumere: Methodology, Data curation, Writing - original draft, Writing - review \& editing. Naomi Codrington: Methodology, Data curation, Writing - review \& editing. Latchman Somenarain: Methodology, Data curation, Writing - original draft. Stephen Redenti: Conceptualization, Investigation, Writing - review \& editing.

\section{Declaration of Competing Interest}

The authors declare that they have no conflict of interest.

\section{References}

Abramicheva, P.A., Smirnova, O.V., 2019. Prolactin receptor isoforms as the basis of tissue-specific action of prolactin in the norm and pathology. Biochemistry (Mosc.) 84 (4), 329-345.

Alvaro, T., Lejeune, M., Salvado, M.T., Bosch, R., Garcia, J.F., Jaen, J., Banham, A.H., Roncador, G., Montalban, C., Piris, M.A., 2005. Outcome in Hodgkin's lymphoma 
can be predicted from the presence of accompanying cytotoxic and regulatory $\mathrm{T}$ cells. Clin. Cancer Res. 11 (4), 1467-1473.

Aravinth, S.P., Rajendran, S., Li, Y., Wu, M., Yi Wong, A.H., Schwarz, H., 2019. EpsteinBarr virus-encoded LMP1 induces ectopic CD137 expression on Hodgkin and ReedSternberg cells via the PI3K-AKT-mTOR pathway. Leuk. Lymphoma 60 (11), 2697-2704.

Das, R., Vonderhaar, B.K., 1996. Involvement of SHC, GRB2, SOS and RAS in prolactin signal transduction in mammary epithelial cells. Oncogene 13 (6), 1139-1145.

Galsgaard, E.D., Rasmussen, B.B., Folkesson, C.G., Rasmussen, L.M., Berchtold, M.W., Christensen, L., Panina, S., 2009. Re-evaluation of the prolactin receptor expression in human breast cancer. J. Endocrinol. 201 (1), 115-128.

Genty, N., Paly, J., Edery, M., Kelly, P.A., Djiane, J., Salesse, R., 1994. Endocytosis and degradation of prolactin and its receptor in Chinese hamster ovary cells stably transfected with prolactin receptor cDNA. Mol. Cell. Endocrinol. 99 (2), 221-228.

Gharbaran, R., Zhang, B., Valerio, L., Onwumere, O., Wong, M., Mighty, J., Redenti, S., 2019. Effects of vitamin D3 and its chemical analogs on the growth of Hodgkin's lymphoma, in vitro. BMC Res. Notes 12 (1), 216.

Griffith, O.L., Chan, S.R., Griffith, M., Krysiak, K., Skidmore, Z.L., Hundal, J., Allen, J.A., Arthur, C.D., Runci, D., Bugatti, M., Miceli, A.P., Schmidt, H., Trani, L., Kanchi, K.L., Miller, C.A., Larson, D.E., Fulton, R.S., Vermi, W., Wilson, R.K., Schreiber, R.D., Mardis, E.R., 2016. Truncating prolactin receptor mutations promote tumor growth in murine estrogen receptor-alpha mammary carcinomas. Cell Rep. 17 (1), 249-260.

Hachim, I.Y., Hachim, M.Y., Lopez, V.M., Lebrun, J.J., Ali, S., 2016. Prolactin receptor expression is an independent favorable prognostic marker in human breast Cancer. Appl. Immunohistochem. Mol. Morphol. 24 (4), 238-245.

Harbaum, L., Pollheimer, M.J., Bauernhofer, T., Kornprat, P., Lindtner, R.A. Schlemmer, A., Rehak, P., Langner, C., 2010. Clinicopathological significance of prolactin receptor expression in colorectal carcinoma and corresponding metastases. Mod. Pathol. 23 (7), 961-971.

Lamprecht, B., Kreher, S., Anagnostopoulos, I., Johrens, K., Monteleone, G., Jundt, F., Stein, H., Janz, M., Dorken, B., Mathas, S., 2008. Aberrant expression of the Th2 cytokine IL-21 in Hodgkin lymphoma cells regulates STAT3 signaling and attracts Treg cells via regulation of MIP-3alpha. Blood 112 (8), 3339-3347.

Lopez-Pulido, E.I., Munoz-Valle, J.F., Del Toro-Arreola, S., Jave-Suarez, L.F., BuenoTopete, M.R., Estrada-Chavez, C., Pereira-Suarez, A.L., 2013. High expression of prolactin receptor is associated with cell survival in cervical cancer cells. Cancer Cell Int. 13 (1), 103.

Martini, M., Hohaus, S., Petrucci, G., Cenci, T., Pierconti, F., Massini, G., Teofili, L., Leone, G., Larocca, L.M., 2008. Phosphorylated STAT5 represents a new possible prognostic marker in Hodgkin lymphoma. Am. J. Clin. Pathol. 129 (3), 472-477.

Matera, L., Geuna, M., Pastore, C., Buttiglieri, S., Gaidano, G., Savarino, A., Marengo, S. Vonderhaar, B.K., 2000. Expression of prolactin and prolactin receptors by nonHodgkin's lymphoma cells. Int. J. Cancer 85 (1), 124-130.

Maus, M.V., Reilly, S.C., Clevenger, C.V., 1999. Prolactin as a chemoattractant for human breast carcinoma. Endocrinology 140 (11), 5447-5450.
Perrot-Applanat, M., Gualillo, O., Buteau, H., Edery, M., Kelly, P.A., 1997. Internalization of prolactin receptor and prolactin in transfected cells does not involve nuclear translocation. J. Cell. Sci. 110 (Pt 9), 1123-1132.

Ramirez de Arellano, A., Lopez-Pulido, E.I., Martinez-Neri, P.A., Estrada Chavez, C., Gonzalez Lucano, R., Fafutis-Morris, M., Aguilar-Lemarroy, A., Munoz-Valle, J.F., Pereira-Suarez, A.L., 2015. STAT3 activation is required for the antiapoptotic effects of prolactin in cervical cancer cells. Cancer Cell Int. 15, 83.

Sackmann-Sala, L., Chiche, A., Mosquera-Garrote, N., Boutillon, F., Cordier, C., Pourmir, I., Pascual-Mathey, L., Kessal, K., Pigat, N., Camparo, P., Goffin, V., 2014. Prolactin-induced prostate tumorigenesis links sustained Stat5 signaling with the amplification of basal/stem cells and emergence of putative luminal progenitors. Am. J. Pathol. 184 (11), 3105-3119.

Scheeren, F.A., Diehl, S.A., Smit, L.A., Beaumont, T., Naspetti, M., Bende, R.J., Blom, B., Karube, K., Ohshima, K., van Noesel, C.J., Spits, H., 2008. IL-21 is expressed in Hodgkin lymphoma and activates STAT5: evidence that activated STAT5 is required for Hodgkin lymphomagenesis. Blood 111 (9), 4706-4715.

Shemanko, C.S., 2016. Prolactin receptor in breast cancer: marker for metastatic risk. J. Mol. Endocrinol. 57 (4), R153-R165.

Shiu, R.P., Elsholtz, H.P., Tanaka, T., Friesen, H.G., Gout, P.W., Beer, C.T., Noble, R.L., 1983. Receptor-mediated mitogenic action of prolactin in a rat lymphoma cell line. Endocrinology 113 (1), 159-165.

Sundaram, K.M., Zhang, Y., Mitra, A.K., Kouadio, J.K., Gwin, K., Kossiakoff, A.A., Roman, B.B., Lengyel, E., Piccirilli, J.A., 2017. Prolactin receptor-mediated internalization of imaging agents detects epithelial ovarian Cancer with enhanced sensitivity and specificity. Cancer Res. 77 (7), 1684-1696.

Taylor, B.S., Schultz, N., Hieronymus, H., Gopalan, A., Xiao, Y., Carver, B.S., Arora, V.K., Kaushik, P., Cerami, E., Reva, B., Antipin, Y., Mitsiades, N., Landers, T., Dolgalev, I., Major, J.E., Wilson, M., Socci, N.D., Lash, A.E., Heguy, A., Eastham, J.A., Scher, H.I., Reuter, V.E., Scardino, P.T., Sander, C., Sawyers, C.L., Gerald, W.L., 2010. Integrative genomic profiling of human prostate cancer. Cancer Cell 18 (1), 11-22.

Uphoff, C.C., Gignac, S.M., Drexler, H.G., 1992. Mycoplasma contamination in human leukemia cell lines. I. Comparison of various detection methods. J. Immunol. Methods 149 (1), 43-53.

Uphoff, C.C., Meyer, C., Drexler, H.G., 2002. Elimination of mycoplasma from leukemialymphoma cell lines using antibiotics. Leukemia 16 (2), 284-288.

Utama, F.E., Tran, T.H., Ryder, A., LeBaron, M.J., Parlow, A.F., Rui, H., 2009. Insensitivity of human prolactin receptors to nonhuman prolactins: relevance for experimental modeling of prolactin receptor-expressing human cells. Endocrinology 150 (4), 1782-1790.

Wallentine, J.C., Kim, K.K., Seiler 3rd, C.E., Vaughn, C.P., Crockett, D.K., Tripp, S.R., Elenitoba-Johnson, K.S., Lim, M.S., 2007. Comprehensive identification of proteins in Hodgkin lymphoma-derived Reed-Sternberg cells by LC-MS/MS. Lab. Invest. 87 (11), 1113-1124. 